\title{
AGE, BODY MASS INDEX AND SEVERITY OF PRIMARY CHRONIC VENOUS DISEASE
}

\author{
Dalibor Musila*, Marketa Kaletova $^{\mathrm{a}}$, Jiri Herman ${ }^{\mathrm{b}}$
}

\author{
a Department of Internal Medicine I - Cardiology, Palacky University Olomouc, Czech Republic \\ ${ }^{b}$ Department of Surgery II - Vascular and Transplantation Surgery, Palacky University Olomouc \\ E-mail: musil.dalibor@gmail.com
}

Received: July 7, 2011; Accepted: October 6, 2011; Available online: November 8, 2011

Key words: Chronic venous disease/Risk factors/Age/Body Mass Index

Aim. The aim of this cross-sectional prospective study was investigate whether there is a correlation between age, BMI and severity of chronic venous disease (CVD), evaluated clinically (CEAP classification) and anatomically (extent of the epifascial venous reflux).

Methods. 213 patients, 65 males ( $30.5 \%$, mean age $45.1 \pm 13.9$ years) and 148 females ( $69.5 \%$, mean age $47.5 \pm 13.5$ years) were divided into three age categories: $18-40$ years $(40.8 \%)$, $41-74$ years $(56.3 \%)$ and 275 years $(2.8 \%)$. BMI was classified as normal weight $\left(18.5-<25 \mathrm{~kg} / \mathrm{m}^{2}\right)$, overweight $\left(25-<30 \mathrm{~kg} / \mathrm{m}^{2}\right)$ and obesity $\left(\geq 30 \mathrm{~kg} / \mathrm{m}^{2}\right)$. Clinical examination of the lower limbs assessed presence and severity of venous signs as included in the CEAP classification. BMI was calculated. Anatomical extent of CVD was described as the number of segments of the superficial and perforating veins with documented reflux by duplex imaging.

Results. Median age increased the number of insufficient venous segments ( 1 insufficient venous segment - median age 41.0 years, 5 insufficient venous segments - median age 51.0 years). The frequency of reflux in the superficial and perforating veins significantly increased with age $(\mathrm{p}<0.05)$. A statistically significan correlation was also found between age and the CEAP classification $(p<0.01)$. This was more significant than the correlation between age and number of insufficient venous segments. In the whole group and in women the Spearman's correlation analysis revealed only a weak positive correlation between BMI and reflux in the superficial veins $(r=0.145$ respectively $r=0.264)(p<0.05)$. No correlation was found in men ( $\mathrm{r}=0.091)$. Weak positive correlation between BMI and stage of venous insufficiency (CEAP classification) was demonstrated for the whole group of patients $(\mathrm{r}=0.229, \mathrm{p}<0.01)$, for women $(\mathrm{r}=0.293$, $\mathrm{p}<0.05)$ and for men $(\mathrm{r}=0.245, \mathrm{p}<0.01)$. Multiple linear regression showed age $(\mathrm{p}<0.0001)$ and BMI $(\mathrm{p}=0.049)$ as significant predictors of clinical grade according to the CEAP classification and the CEAP clinical class $(p<0.0001)$ as a significant predictor of extent of the epifascial venous reflux.

Conclusions. The study confirmed the relationship between age, clinical (CEAP clinical class) and pathophysiological (extent of the venous reflux) severity of CVD. Older age means an increased number of insufficient venous segments and increased risk of the clinical progression of CVD from varicose veins to chronic venous insufficiency $\left(\mathrm{C}_{3}-\mathrm{C}_{6}\right.$, trophic skin changes and venous ulcers). Our results support the BMI, in term of frequency of venous reflux, as a risk factor in the whole group of patients but only in women but not in men. Multiple linear regression showed BMI together with age as significant predictors of clinical grade of CVD $(p<0.05)$ according to the CEAP classification. As regards the influence of BMI on clinical severity/grade of CVD (CEAP), the results of our study support BMI as an important risk factor.

\section{INTRODUCTION}

Chronic venous disease (CVD) is one of the most common disorders in European countries. The cross-sectional Edinburgh Vein Study found that telangiectases and reticular veins were each present in approximately $80 \%$ of men and $85 \%$ of women ${ }^{1}$. Risk factors for CVD include heredity, age, female sex, obesity, pregnancy, prolonged standing and greater height ${ }^{2}$. Age and obesity have been also described to promote varicosity $1,3,5$.

Age was the most important risk factor for varicose veins $\left(\mathrm{C}_{1}-\mathrm{C}_{2}\right.$, according to the $\left.\mathrm{CEAP}\right)$ and chronic venous insufficiency $\left(\mathrm{C}_{3}-\mathrm{C}_{6}\right.$, according to the CEAP $)$ in all recent studies ${ }^{6-9}$. The role of obesity was controversial. Some studies have found increased the risk of varicose veins in overweight and obesity ${ }^{3,8,9}$ but not other studies ${ }^{6,7}$. In addition, some studies have found different risk for women and for men. These studies showed a positive association of increased Body Mass Index (BMI) with varicose veins in women ${ }^{3,9}$ or only in postmenopausal women ${ }^{10}$ but not in men. For this reason, our study focused on age as one of the main risk factors and on BMI as one of the controversial risk factors for CVD. With increasing risk (older age and increasing BMI) we can assume more severe manifestation of CVD. A significant risk factor should be meet this criterion.

The aim of our study was to determine wheter there is a statistical significant correlation between age, BMI and severity of primary chronic venous disease. 


\section{MATERIALS AND METHODS}

This cross-sectional prospective study was conducted in patients who presented to the vascular department with signs and symptoms of chronic venous disease classified as primary with undetermined cause $\left(\mathrm{E}_{\mathrm{p}}\right.$, according to the CEAP) (ref. ${ }^{11,12}$ ). Clinical examination of the lower limbs assessed the presence and severity/grade of venous signs as included in the CEAP classification and was performed while the patients were standing. The height and weight of patients were obtained and the BMI was calculated. Anatomical extent of reflux in the lower limbs $\left(\mathrm{P}_{\mathrm{R}}\right.$, according to the CEAP) (ref. $\left.{ }^{11,12}\right)$ was described as the number of segments of the superficial and perforating veins with documented reflux by duplex evaluation (Table 1). The severity of CVD was graduated based on the clinical CEAP classification $\left(\mathrm{C}_{1}-\mathrm{C}_{6}\right)$ and according to the number of insufficient anatomical venous segments of the lower limb (1-6 anatomical segments, according to the CEAP) (ref. ${ }^{11,12}$ ).

\section{Patients}

The subjects studied were: 213 patients, 65 males (30.5\%, mean age $45.1 \pm 13.9$ years) and 148 females ( $69.5 \%$, mean age $47.5 \pm 13.5$ years). Patients were divided into three age categories: $18-40$ years $(40.8 \%), 41-74$ years $(56.3 \%)$ and 275 years $(2.8 \%)$. BMI was classified as: normal weight $\left(18.5-<25 \mathrm{~kg} / \mathrm{m}^{2}\right)$, overweight $(25-$ $\left.<30 \mathrm{~kg} / \mathrm{m}^{2}\right)$ and obesity $\left(\geq 30 \mathrm{~kg} / \mathrm{m}^{2}\right)$ (WHO, 2004) (ref. $\left.{ }^{13}\right)$.

\section{Statistics}

Statistical analysis was performed using the version of the SPSS 15.0 software (SPSS Inc., Chicago, USA). To assess the dependence, the non parametric Spearman's correlation analysis was used. Groups of patients by age and BMI categories were compared for number of insufficient venous segments using the Kruskal-Wallis's test. In the case of significant result of the Kruskal-Wallis test, two sets of results were compared by the Mann-Whitney test with significance corrected according to Bonferroni. Normality of data was verified using the Shapiro-Wilk's test. Values of $p<0.05$ were taken to be statistically significant.
Table 1. Anatomical segments of the superficial and perforating veins according to CEAP classification (Consensus statement, 1995, 2004) (ref. ${ }^{11,12}$ ).

\begin{tabular}{|l|}
\hline Telangiectases/reticular veins \\
\hline Great saphenous vein above knee \\
\hline Great saphenous vein below knee \\
\hline Short saphenous vein \\
\hline Non-saphenous vein \\
\hline Perforating veins on the thigh and/or calf \\
\hline
\end{tabular}

\section{RESULTS}

Men in studied group were younger than women (mean age $45.1 \pm 13.9$ years vs $47.5 \pm 13.5$ years) and had significantly higher BMI (men: mean BMI 26.9 \pm 3.3 $\mathrm{kg} / \mathrm{m}^{2}$, women: mean BMI $25.1 \pm 4.1 \mathrm{~kg} / \mathrm{m}^{2}$ ). Mean BMI value in the whole group $\left(25.6 \mathrm{~kg} / \mathrm{m}^{2}\right)$, men $\left(26.9 \mathrm{~kg} / \mathrm{m}^{2}\right)$ and women $\left(25.1 \mathrm{~kg} / \mathrm{m}^{2}\right)$ were overweight in the band (Table 2). The most frequent CEAP clinical classes were $\mathrm{C}_{2}$ - varicose veins (113 legs, $53.1 \%$ ) and $\mathrm{C}_{3}$ - telangiectases or reticular veins or varicose veins with moderate to severe oedema ( 51 legs, $23.9 \%$ ) (Table 3 , left). $8 \%$ patients had only 1 insufficient anatomical venous segment, $92 \%$ patients have $\geq 2$ insufficient segments, $68.5 \%$ patients have $\geq 3$ insufficient segments, $22 \%$ patients have $\geq 4$ insufficient segments and $4.2 \%$ patients have 5 insufficient venous segments (Table 3 , right).

Table 2. BMI.

\begin{tabular}{|l|c|c|c|c|}
\hline \multirow{2}{*}{} & \multicolumn{4}{|c|}{ BMI $\left(\mathrm{kg} / \mathrm{m}^{2}\right)$} \\
\cline { 2 - 5 } & min. & max. & mean & SD \\
\hline Men & 18.0 & 37.9 & 26.9 & \pm 3.3 \\
\hline Women & 18.0 & 37.6 & 25.1 & \pm 4.1 \\
\hline All patients & 18.0 & 37.9 & 25.6 & \pm 4.0 \\
\hline
\end{tabular}

Table 3. Distribution of patients according to the clinical CEAP classification and the number of insufficient venous segments.

\begin{tabular}{|c|c|c|c|c|c|}
\hline $\begin{array}{c}\text { CEAP } \\
\text { classification }\end{array}$ & Frequency & Percentage & $\begin{array}{c}\text { The number } \\
\text { of insuff. venous } \\
\text { segments }\end{array}$ & Frequency & Percentage \\
\hline C1 & 29 & 13.6 & 1 & 17 & 8.0 \\
\hline C2 & 113 & 53.1 & 2 & 67 & 31.5 \\
\hline C3 & 51 & 23.9 & 3 & 82 & 38.5 \\
\hline C4 & 15 & 7.0 & 4 & 38 & 17.8 \\
\hline C5 & 1 & 0.5 & 5 & 9 & 4.2 \\
\hline C6 & 4 & 1.9 & 6 & 0 & 0 \\
\hline Total & 213 & 100.0 & & 213 & 100.0 \\
\hline
\end{tabular}


1. Age and severity of chronic venous disease

Relationship between the number of insufficient venous segments and age characteristics of patients in our group is shown in Table 4 . In this table the more venous segments with reflux means the higher median age. Median age for 1 insufficient venous segment is 41.0 years, for 5 insufficient venous segments 51.0 years.

Spearman's correlation analysis showed significant positive correlation between age and extent of reflux in the superficial and perforating venous segments. Significantly more insufficient venous segments was found in patients aged $\geq 75$ years (mean $3.5 \pm 0.55$ insuff. segments) compare with patients aged $\leq 40$ years (mean $2.63 \pm 0.92$ insuff. segments $)(p=0.049)$. The number of insufficient venous segments increased with age (Fig. 1).

Statistically significant correlation was also found between age and the clinical CEAP classification. When we checked the relationship between age and the number of insufficient venous segments, age and BMI, age and the CEAP clinical class of venous disease, Spearman's correlation analysis showed the strongest correlation between age and CEAP clinical class (correlation coefficient: $r=0.379)(p<0.01)$. This correlation was more significant than the correlation between age and number of insufficient venous segments.

\section{BMI and severity of chronic venous disease}

In the whole group of patients and in women the Spearman's correlation analysis revealed a weak positive correlation between BMI and reflux in superficial veins $(r=0.145$ respectively $r=0.264)(p<0.05)$. No correlation was found in men $(r=0.091)$. Kruskal-Wallis test showed no significant difference in the number of insufficient venous segments depending on the categorization of BMI $(p=0.290)$. Frequency of venous reflux did not increase with BMI (Fig. 2). Weak positive correlation between BMI and clinical stage of venous insufficiency according to the CEAP classification was demonstrated for the whole group of patients $(\mathrm{r}=0.229, \mathrm{p}<0.01)$, for women $(\mathrm{r}=0.293, \mathrm{p}<0.05)$ and for men $(\mathrm{r}=0.245, \mathrm{p}<0.01)$.

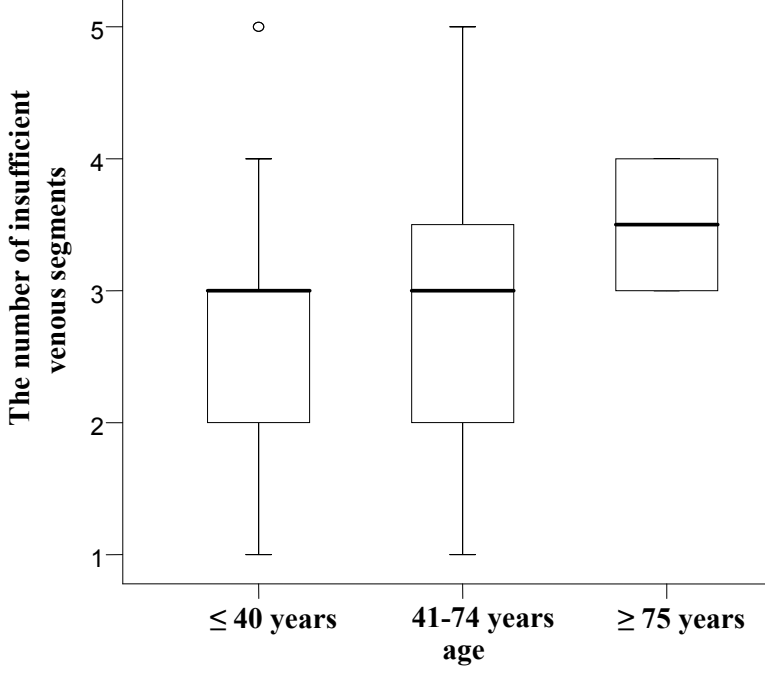

Fig. 1. Distribution of the number of insufficient venous segments depending on three age categories.

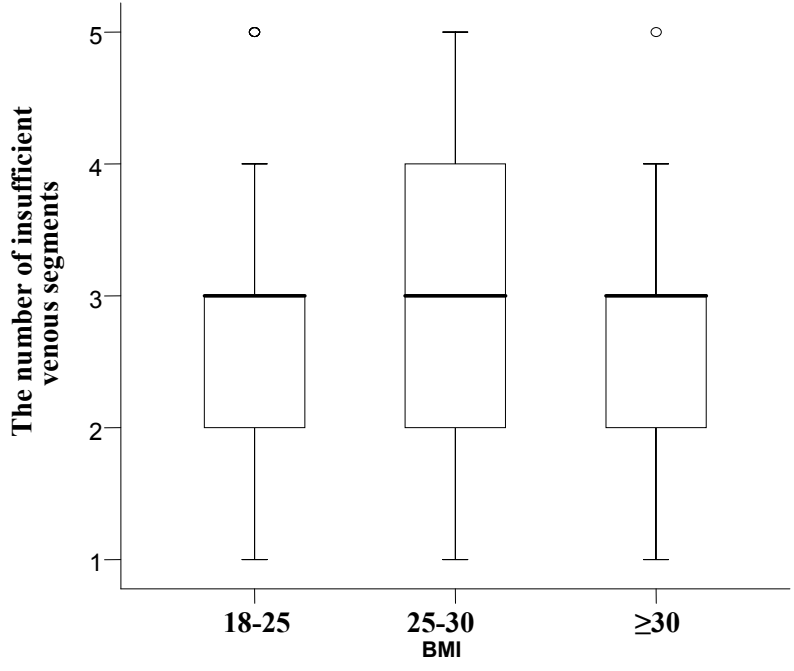

Fig. 2. Distribution of the number of insufficient venous segments depending on BMI in the whole group of patients.

Table 4. Age characteristics of patients according to the number of insufficient venous segments.

\begin{tabular}{|c|c|c|c|c|c|}
\hline \multirow{2}{*}{$\begin{array}{c}\text { Number of insuff. } \\
\text { venous segments }\end{array}$} & \multirow{2}{*}{$\begin{array}{c}\text { Number } \\
\text { of patients }\end{array}$} & \multicolumn{4}{|c|}{ Age characteristics (years) } \\
\cline { 3 - 6 } & 17 & 18 & 70 & 41.0 & 13.0 \\
\hline 1 & 67 & 24 & 73 & 41.0 & 12.2 \\
\hline 2 & 82 & 21 & 82 & 44.0 & 13.9 \\
\hline 3 & 38 & 26 & 78 & 50.5 & 14.9 \\
\hline 4 & 9 & 33 & 70 & 51.0 & 12.5 \\
\hline 5 & & & & & maximum \\
\hline
\end{tabular}

SD - Standard deviation 
In multiple linear regression to predict the clinical severity/grade of chronic venous disease according to the CEAP classification, we used as the independent parameters age and BMI. Significant predictors of clinical severity/grade were both: age $(p<0.0001)$ and BMI $(p<0.049)$.

In multiple linear regression to predict the number of insufficient anatomical venous segments of the lower limb we used as the independent parameters age, BMI and CEAP clinical class. Significant predictor of extent of the epifascial venous reflux was only the CEAP clinical class $(\mathrm{p}<0.0001)$.

\section{DISCUSSION}

This study was designed to investigate whether there is a correlation between age, BMI and severity of primary chronic venous disease, evaluated clinically (CEAP classification) and anatomically (extent of the epifascial venous reflux assessed by ultrasound).

Age is a well-known risk factor for development of CVD. Age was recognised as the most important risk in early epidemiologic studies and also in recent epidemiologic studies, incorporated the CEAP classification, clinical and duplex evaluation into the study design $n^{6,7}$. Older cross sectional studies have been based on self-assessed diagnosis and the clinical classification of the varicose veins has not been adapted to the CEAP classification, which is now recommended. The proportion of disease risk attributable to age and sex, the two main risk factors for CVD was estimated as $10.7 \%\left(\right.$ ref. $\left.^{4}\right)$. Age is not associated only with formation (primary cause?) but also with progression of CVD. Age together with varicose veins and pitting oedema are considered the most important risk for trophic skin changes ${ }^{6}$.

We showed a significant positive correlation between age and number of insufficient venous segments $(p<0.05)$. Median age increased the number of insufficient venous segments. Age was also very significant predictor of clinical grade of CVD, according to the CEAP classification $(p<0.0001)$. According to some studies, the presence of epifascial venous reflux correlates positively with increasing CEAP grade of visible disease $(p<0.0001)$ for all superficial venous segments ${ }^{15}$. Our results support these findings because a very significant predictor of the extent of the epifascial venous reflux was CEAP clinical class $(p<0.0001)$. It means that clinical progression of chronic venous disease (CEAP) is accompanied by progression of reflux in the superficial veins and both clinical progression and progression of superficial venous reflux significantly correlate with age. Thus, this study confirmed the relationship between age and severity of chronic venous disease, both from the pathophysiological and clinical point of view. Older age means increased number of insufficient venous segments, increased CEAP grade of visible disease and increased risk of the clinical progression from varicose veins to chronic venous insufficiency $\left(\mathrm{C}_{3}-\mathrm{C}_{6}\right.$, trophic skin changes and venous ulcers $)$.

The evidence on BMI for CVD was inconclusive. Obesity has been suggested as a risk factor in women, but apears to be an aggravating factor rather then a primary cause $^{14}$. According to some recent works the frequency of both, visible and functional venous disease, increase with $\mathrm{BMI}^{15}$ and overweight is a risk factor for increased prevalence of skin changes and venous ulcer ${ }^{16}$. We found a positive correlation between increased BMI and frequency of venous reflux and between increased BMI and clinical severity/grade of CVD, according to the CEAP classification, in the whole group of patients and in women. In men the correlation was found only between BMI and clinical severity/grade of visible disease. Multiple linear regression showed BMI together with age as significant predictors of clinical grade of CVD ( $p<0.05)$ according to CEAP classification. Therefore, as regards the influence of BMI on clinical severity/grade of CVD (CEAP), the results of our study support the BMI as an important risk factor. Obese patients have clinicaly more severe venous disease.

\section{REFERENCES}

1. Evans CJ, Fowkes FGR, Ruckley CV, Lee AJ. Prevalence of varicose veins and chronic venous insufficiency in men and women in the general population: Edinburgh Vein Study. J Epidemiol Community Health 1999;53:149-53.

2. Bergan JJ, Schmid-Schönbein GW, Coleridge Smit, PD, Nicolaides AN, Boisseau MR, Eklof B. Chronic venous disease. N Engl J Med 2006;355:488-8.

3. Brand, FN, Dannenberg, AL, Abbott, RD, Kannel, WB: The epidemiology of varicose veins: the Framingham Study. Am J Prev Med 1988; 4:96-101

4. Fiebig A, Krusche P, Wolf A, Krawczak M, Timm B, Nikolaus S, Frings N, Schreiber S: Heretability of chronic venous disease. Hum Genet 2010;40:650-9.

5. Laurikka J, Sisto T, Auvinen O, Tarkka M, Läärä E, Hakama M. Varicose veins in a Finnish population aged 40-60. J Epidemiol Community Health 1993;48:212-3.

6. Carpentier PH, Maricq HR, Biro C, Ponçot-Makinen CO, Franco A. Prevalence, risk factors and clinical patterns of chronic venous disorders of lower limbs: a population-based study in France. J Vasc Surg 2004;40:650-9.

7. Chiesa R, Marone EM, Limoni C, Volonté M, Schaefer E, Petrini O. Chronic venous insufficiency in Italy: the 24-Cities-Cohort Study. Eur J Vasc Endovasc Surg 2005;30:422-9.

8. Jawien A, Grzela T, Ochwat A: Prevalence of chronic venous insufficiency in men and women in Poland: multicenter cross-sectional study in 40095 patients. Phlebology 2003;18:110-2.

9. Rabe E, Pannier-Fischer F, Bromen K. Bonner Venenstudie der Deutschen Gesellschaft für Phlebologie - epidemiologische Untersuchung zur Frage der Häufigkeit und Ausprägung von chronischen Venenkrankheiten in der städtischen und ländlichen Wohnbevölkerung. Phlebologie 2003;32:1-14.

10. Iannuzzi A, Panico S, Ciardullo AV, Bellati C, Cioffi V, Iannuzzo G, Celentano E, Berrino F, Rubba P. Varicose veins of the lower limbs and venous capacitance in postmenopausal women: Relationship with obesity. J Vasc Surg 2002;36:965-8.

11. Consensus statement. Classification and Grading of Chronic Venous Disease in the Lower Limbs: A Consensus Statement. Phlebology 1995;10:42-5.

12. Eklof B, Rutherford RB, Bergan JJ, Carpentier PH, Gloviczki P, Kistner RL, Meissner MH, Moneta GL, Myers K, Padberg FT, Perrin M, Ruckley CV, Smith PC, Wakefield TW. Revision of the CEAP classification of chronic venous disorders. Consensus statement. J Vasc Surg 2004;40:1248-52.

13. WHO expert consultation: Appropriate body-mass index for Asian population and its implications for policy and intervetion strategies. Lancet 2004;363:1077. 
14. Robertson L, Evans CJ, Fowkers FG.: Epidemiology of chronic venous disease. Phlebology 2008;23:103-11.

15. Chiesa R, Marone EM, Limoni C, Volonté M, Petrini O: Chronic venous disorders: correlation between visible signs, symptoms, and presence of functional disease. J Vasc Surg 2007;46:322-30.

16. Danielsson G, Eklof B, Grandinetti A, Kistner LR: The influence of obesity on chronic venous disease. Vasc Endovasc Surg 2002;36:271-6. 
